\section{LONG-EARED OWL SNAGGED ON BARBED-WIRE FENCE}

Recent summaries of bird deaths on barbed-wire fences, while listing many species of diurnal and nocturnal raptors, fail to mention that the long-eared owl is "locally common in woods near open country." They often exist in close association with such fences and some snagging- or hanging-related deaths would be expected. ${ }^{1,2}$

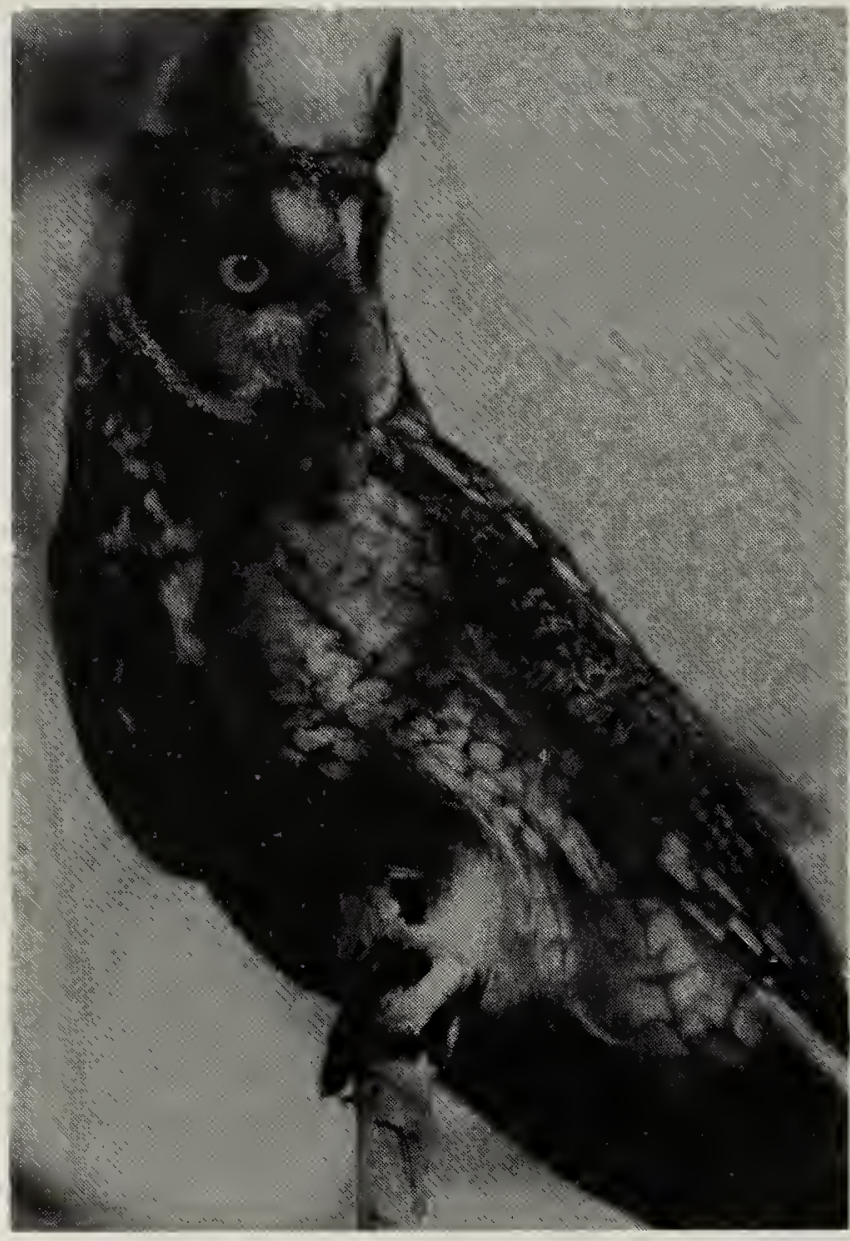

Long-eared Owl

Wayne Lynch

On 16 July 1993 we discovered a dead long-eared owl hanging from a barbed-wire fence near Villa Grove, along U.S. Highway 285 , in the San Luis Valley of south central Colorado. The owl was caught on a barb by its left wing and apparently hung, suspended freely, until its death. We estimated the bird had been dead 57 days. This specimen, although collected, was later lost to scavengers, precluding sex determination or aging. Given the season and the inex- perience of young of the year, however, it is reasonable to suspect that the owl was a recent fledgling.

As owl authority Denver Holt has pointed out (personal communication), wildlife deaths due to encounters with fences are really no different from other forms of humanrelated mortality such as electrocution, poisoning, collisions with automobiles, power lines, or windows, etc. The significance of barbed-wire related deaths, while likely minor, would more fully be appreciated with quantifiable data from surveys similar in design to those used for assessing power line- and radio tower-related mortality.

Special thanks are extended to Robert Nero, who thoughtfully provided information on barbed-wire fence related deaths, and to Richard Reynolds and Denver Holt for manuscript review.

1. Allen, George T. and Pedro Ramirez. 1990 A review of bird deaths on barbed-wire fences. Wilson Bull. 102(3):553-558

2. Nero, Robert $W$. Northern flying squirrel and red bat caught on barbedwire. 1993. Blue Jay 51(4):215-216

- JAY W. TISCHENDORF* AND CHARLES L. JOHNSON, United States Forest Service, Rocky Mountain Forest and Range Experiment Station, 240 West Prospect Road, Fort Collins, Colorado 80526 U.S.A.

*Present address: American Ecological Research Institute, AERIE, Post Office Box 380, Fort Collins, Colorado 80522 and Colorado State University, College of Veterinary Medicine and Biomedical Sciences, Fort Collins, Colorado 80523 